\title{
DOLOR Y MEMORIA. UNA MIRADA FILOSÓFICA A PARTIR DE SHIBBOLETH DE DORIS SALCEDO
}

\author{
Manuel Oswaldo Ávila Vásquez* \\ doi:10.11144/Javeriana.uph32-64.dmds
}

\begin{abstract}
RESUMEN
El texto plantea una reflexión a partir de la obra Shibboleth de la escultora colombiana Doris Salcedo, en torno a la relación entre dolor y memoria, cuyo telón de fondo es el conflicto armado colombiano. Más exactamente, insiste en la relevancia que tiene la memoria en la conformación de la historia auténtica de una comunidad; o, en palabras de Beuys, es muy importante mostrar las heridas a la hora de pretender hallar la cura de una sociedad gravemente enferma por un conflicto que ha regado con la sangre de los nacidos allí una tierra que, se quiera o no, les resulta común. Palabras clave: Doris Salcedo; Shibboleth; heridas; dolor; memoria
\end{abstract}

* Universidad Pedagógica y Tecnológica de Colombia, Tunja, Colombia.

Correo electrónico: manuelavilavasquez@gmail.com

Para citar este artículo: Ávila VÁsquez, M.O. (2015). Dolor y memoria. Una mirada filosófica a partir de Shibboleth de Doris Salcedo. Universitas Philosophica, 32(64), pp. 153-178, ISSN 01205323, ISSN en línea: 2346-2426, doi: 10.11144/ Javeriana.uph32-64.dmds 


\title{
PAIN AND MEMORY. A PHILOSOPHICAL REGARD FROM DORIS SALCEDO'S SHIBBOLETH
}

\author{
Manuel Oswaldo Ávila Vásquez
}

\begin{abstract}
The text brings a reflection on pain and memory relationship from Colombian sculptor Doris Salcedos's work Shibboleth, whose background is the current Colombian armed conflict. More precisely, it emphasizes on the relevance of memory in a community's authentic historical configuration. Or, in Beuys' words, showing the wounds is highly important when trying to find cure and healing for a serious ill society, bathed in a bloody conflict between those born there, a land that, like it or not, it's found to be common for all of us.
\end{abstract}

Key words: Doris Salcedo; Shibboleth; wounds; pain; memory 


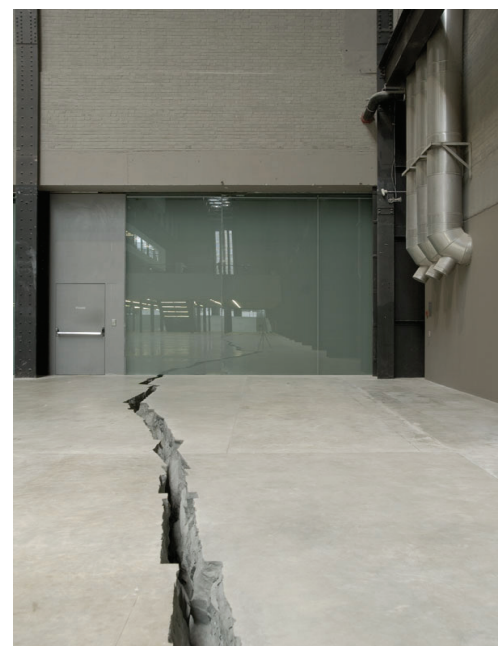

Doris Salcedo. Shibboleht.

Tate Modern, Londres, 2007. Fotografia: Sergio Clavijo.

Para que algo permanezca en la memoria se lo graba con fuego; solo lo que no cesa de doler permanece en la memoria.

F. Nietzsche

\section{Introducción}

DE LO QUE SE TRATA AQUí ES DE IR tras las heridas de lo que somos. ¿Y qué otra cosa podría ser en una época y en un país caracterizados por el conflicto y el desgarramiento, esto es, en una época en la que los seres humanos están habituados a sangrientos atentados y revueltas “populares”, la práctica de la tortura por parte de miembros de ejércitos invasores y la crisis económica? En otras palabras, ir tras el origen de esa inmensa fractura que ha caracterizado la relación de los hombres entre sí y con todo lo que existe hasta el día de hoy, la cual ha terminado acentuándose en la Era moderna, hasta el punto de identificarse con el Zeitgeist, como solía expresarse Hegel. En último término, ir tras la búsqueda de la fuente de nuestra 
propia herida, como aquella que se hizo arte, en forma de grieta, por Doris Salcedo, escultora colombiana, en su obra Shibboleth, del año 2007.

Habrá que decir que Shibboleth evidencia, quizá como ninguna obra de arte antes, de manera tan directa, la fractura propia de una época signada por el espíritu de la escisión al modo como lo vio Hegel ${ }^{1}$. Así que, Shibboleth no solo sería una monumental grieta, una especie de herida, de 167 metros de largo por 50 centímetros de ancho sino, dicho en el espíritu de la propia escultora, una creación artística que señala la profunda fisura que aún existe entre los seres humanos, los cuales, o bien son percibidos como ciudadanos propiamente humanos o, por el contrario, son vistos por otros seres humanos como carentes de ciudadanía y de humanidad. Asimismo, esta obra haría patente la grieta existente entre dos mundos que nunca convergen (Toledo, 2007), la cual caracterizaría nuestro propio tiempo y, desde luego, las relaciones entre los seres humanos en nuestro propio país.

En breves palabras, lo que queremos mostrar aquí es la fragilidad misma del ser humano y de sus relaciones. Para ello, nos detenemos a observar esta escultura de una artista colombiana que pertenece a una generación habituada al desplazamiento, a ser testigo de escenas de terror como si fuese algo rutinario;una generación acostumbrada a estar en medio de fuerzas políticas antagónicas en una tierra destrozada y arruinada por la violencia (González, 2010). Prestar atención a una escultura en la que resuena un conflicto de décadas (el conflicto colombiano), el cual parece haberse convertido en una parte esencial de todos los que hemos nacido en este país, es tomarse el tiempo en la contemplación de una obra en la que tal vez sea posible escuchar aquello que Martin Heidegger caracterizó, desde la década de 1930, como una especie de oscurecimiento universal del planeta. [Y cuyas manifestaciones más elocuentes estarían representadas en eso que este filósofo identifica con] "la huida de los dioses, la destrucción de la

1 Si bien, Shibboleth es capaz de captar lo propio de una época marcada por el espíritu de la escisión en su desnuda sencillez, no se puede desconocer que este intento lo llevaron a cabo otros artistas antes de Doris Salcedo. Valga recordar aquí, por ejemplo, obras como: La guerra, de Otto Dix; La Noche, de Max Beckmann; Guernica, de Pablo Picasso y en nuestro medio obras como: Violencia, de Alejandro Obregón; Nueve de abril, de Alipio Jaramillo; Tranvía incendiado, de Enrique Grau; Piel al sol, de Luis Ángel Rengifo; La cosecha de los violentos, de Alfonso Quijano; La horrible mujer castigadora, de Norman Mejía; El martirio agiganta a los hombres de raiz, de Pedro Alcántara o Aliento, de Oscar Muñoz. 
Tierra, la masificación del hombre, la prevalencia de la mediocridad" (Heidegger, 2003, p. 49).

En palabras de Joseph Beuys, aquí queremos atender al llamado que nos hace nuestro tiempo en este preciso lugar de la tierra, para atrevernos así a mostrar nuestras propias heridas, en una época en la que nos hemos empecinado, malignamente, en darle la espalda a lo más esencial que hay en nosotros. Y, no nos referimos con esta afirmación tan solo a lo más abyecto que habita en lo más profundo de nuestra psique, sino a aquello que, junto al placer, constituye nuestro ser más propio: el sufrimiento. En este orden de ideas, ir tras las heridas de lo que somos lleva consigo, en este contexto histórico en el que nos ha correspondido vivir, a una clara decisión política comprometida con el presente, aunque con la vista puesta en el pasado, para ser lanzados decididamente hacia el futuro.

¿Acaso podría esperarse algo radicalmente distinto en un tiempo caracterizado por crueles enfrentamientos entre los hombres, por el incremento de la pobreza y la crisis del medio ambiente? Expresado de otro modo ¿cabría pensar algo diferente en una época en la que parece haberse vuelto moneda corriente eso que el agudo autor del Zaratustra denominaba voluntad de nada? Para llevar a cabo lo que aquí nos proponemos, en primer lugar, como se ha señalado, se identificarán, a partir de algunas consideraciones en torno a Shibboleth de Doris Salcedo, ciertos síntomas de nuestra época. En segundo lugar, se establecerá la relación existente entre el dolor, la memoria y la característica más propia de esta época, a saber: el nihilismo. Finalmente, en tercer lugar, se esbozarán algunas conclusiones a partir de lo dicho. Demos pues inicio a estas consideraciones.

\section{A la escucha de Shibboleth}

LO PRIMERO QUE HAY QUE PREGUNTARSE aquí es: ¿a qué viene esta extraña relación con el arte? ¿No se trata de llevar nuestra época a conceptos, tal modo como lo pretendía Hegel? Todo parece indicarlo, máxime si tenemos en cuenta que la presente indagación brota en el terreno de la filosofía. Sin embargo, nuestra tarea parece desbordar a esta última. Nada raro de una labor que está referida a una época en la que la dura confrontación entre los hombres parece haberse convertido en su rasgo más esencial. De manera más precisa, nada extraño en un tiempo en el que todos los conceptos parecen quedarse cortos. De ahí que, una 
obra como Shibboleth de Doris Salcedo se muestre como una expresión más de algo que parece haberse arraigado en lo hondo de nuestro "inconsciente colectivo" ¿Qué es, empero, ese algo? Tal vez la respuesta la podamos encontrar escudriñando en el sentido mismo de la obra. Veamos.

Como se ha indicado, Shibboleth es una descomunal grieta que debe su nombre a un "pasaje del Antiguo Testamento donde se cuenta cómo los miembros de una tribu mataban a los de otra que pronunciaban esta palabra de manera diferente. (...). Shibboleth, en hebreo, es una palabra que simplemente significa «espiga », «espiga de trigo», pero ha sido un examen de pertenencia o exclusión en diferentes sociedades" (Toledo, 2007). Pero, ante todo, debe su nombre a un emotivo poema de Paul Celan ${ }^{2}$, a quien la artista colombiana no duda en poner al lado de escritores de la talla de Franz Rosenzweig y Friedrich Hölderlin.

No está demás anotar que, para Doris Salcedo, el poema Shibboleth de Paul Celan, al igual que su propia obra, hace "referencia al duelo permanente, porque no hay manera, a través del arte, de recuperar las vidas perdidas. El arte [como la poesía, subraya la artista] es impotente frente a la muerte. (...) [Y,] sin embargo, [tanto el uno como la otra, tienen] una habilidad y es traer al campo de lo humano la vida que ha sido desacralizada y darle una cierta continuidad en la vida del espectador" (Toledo, 2007). Pero, ¿qué expresa el poema de Celan? Atendamos por un momento a lo que este dice:

\section{Shibboleth}

Junto con mis piedras,

las crecidas con llanto

tras las rejas,

me arrastraron

al centro del mercado,

$2 \mathrm{Al}$ respecto Guillermo González manifiesta en el texto arriba citado: "La poesía de Paul Celan se convirtió desde muy temprano en un eje sobre el cual [la artista] trata de estructurarlo todo. Nadie ha sido capaz de llegar al punto de expresar algo en un silencio radical como él, acaso porque fue víctima y a la vez poeta, y al mismo tiempo entraba y salía, dice ella; disponía de todas esas posibilidades y hablaba tantos idiomas, estaba en tantos planos; la existencia simultánea le permitía mantener una distancia increíble de su propia experiencia como víctima; entonces es el huérfano, es el viudo, es la persona confinada, es Celan. Así es, no hay igual, y lleva esa experiencia a tal extremo, que si la llevara un grado más allá, se desarmaría el lenguaje. Lo lleva al límite de la comprensión” (2010). 
allí

donde se despliega la bandera a la que

no presté juramento alguno.

Flauta,

flauta doble de la noche:

recuerda la oscura

rojez gemela

en Viena y en Madrid.

Pon tu bandera a media asta,

recuerdo.

A media asta

para hoy y para siempre.

Corazón:

date a conocer también aquí,

aquí, en el centro del mercado.

Grita el Shibboleth, grítalo

hacia lo extranjero de la patria:

Febrero. No pasarán.

\section{Unicornio:}

tú sabes de las piedras,

tú sabes de las aguas,

ven,

yo te llevaré de aquí

hacia las voces de Extremadura³. (Celan, 1997, p. 95)

3 Vale la pena transcribir aquí la versión hecha de este poema para la edición de las Obras completas de Celan a cargo de José Luis Reina Palazón: "Shibboleth. / Junto con mis piedras, / crecidas en el llanto / detrás de las rejas, / me arrastraron / al centro del mercado, / allí / donde se despliega la bandera, a la que / no presté juramento. / Flauta, / flauta doble de la noche: / piensa en la oscura / aurora gemela / en Viena y Madrid. / Pon tu bandera a media asta, /memoria. / A media asta / hoy para siempre. / Corazón: /date a conocer también / aquí, en medio del mercado. / Dí a voces el Shibboleth / en lo extranjero de la patria: Febrero, no pasarán. / Einhorn: / tú sabes de las piedras, / tú sabes de las aguas, / ven, / yo te llevaré lejos, / a las voces / de Extremadura" (1999, pp. 106-107). Como hace notar este traductor en su nota a pie de página, cuando Celan se refiere a Viena está cavilando en: la "rebelión obrera contra el gobierno Dollfuss en Viena en 1934" (Reina Palazón, 1999, p. 106); cuando se alude a Madrid se refiere, desde luego, a la Guerra Civil Española. Como 
La pregunta ahora es: ¿cómo resuena en Shibboleth de Doris Salcedo, Shibboleth de Paul Celan? Quizá ya se ha reconocido, simplemente, que la obra de la artista como el poema, es un duelo permanente, una bandera a media asta a la que no se prestó juramento, un recuerdo a ejecutar hoy y mañana, un grito al extranjero de una tierra rica en "duelos no elaborados" y en la que "los conflictos no se resuelven sino cuando uno u otro muere" (González, 2010). Empero, ¿qué es realmente Shibboleth? Tal vez la respuesta la tenga el filósofo Jacques Derrida, que consagró, justamente, uno de sus ensayos más complejos a Shibboleth de Paul Celan.

El referido texto, cuyo título completo es: Shibboleth. Para Paul Celan, arranca con una interesante referencia a la circuncisión y al hecho contundente de la imposibilidad de su repetición. Es decir, a un acontecimiento único e irrepetible con el cual, escribe Derrida, puede aproximarse "a lo que [este] puede ofrecer de resistencia al pensamiento. (...) y de lo que una resistencia también $d a$ a pensar" (Derrida, 2002, p. 11)4. En pocas palabras, parte de un dolor, algo así como de una herida, irrepetible, que rememora un acontecimiento fundamental, y el cual ha quedado grabado en lo profundo de "la memoria histórica" de una comunidad ${ }^{5}$. Planteado esto mismo de forma más concreta, se alude con ello a

se puede observar, además, en esta traducción se hace referencia directa a "Erich Einhorn, amigo de Celan. «Unicornio» sería la traducción de su apellido” (Reina Palazón 1999, p. 107).

4 Con razón dice también Fausto teniendo en mente a los viejos Filemón y a Baucis: "La resistencia, la obstinación menoscaban el logro más soberbio" (Goethe, 1968, p. 495).

5 Resulta muy interesante lo escrito por Guillermo González Uribe, a propósito de la memoria histórica en la obra artística de Doris Salcedo: "la memoria histórica -dice- es un tema recurrente en Doris. La importancia de la memoria, lo esencial que es y, en particular, la memoria a largo plazo. La que vivimos hoy es la memoria reciente; entonces las Farc son malas hoy y de ahí para atrás nadie piensa, qué los llevó allá, eso no existe. Israel es malo, pero qué los llevó allá, nadie conecta eso ni siquiera con el Holocausto, que es tan reciente; ni se habla de todas las barbaridades y los errores que cometieron los británicos; nadie dice que los británicos son perversos porque desbarataron el Medio Oriente. Enfatiza en el problema de la memoria reciente, en el desinterés por la historia, por el análisis, y en que no interesa ligar las cosas. Regresa a la importancia de hablar de la memoria histórica, pues nos carga de responsabilidad, y si entendemos qué pasó a largo plazo, nos vamos a ver involucrados en algún momento y tendríamos que hacer algo para reparar ese daño. Sería introducir un concepto de justicia diferente; no la idea que tenemos hoy en día, que a roba a b y por tanto va a la cárcel y se queda fregado por robarle a b. Esto es un acto de venganza: el Estado se va a vengar, pero no hay una restitución; entonces, la memoria histórica involucra la necesidad de restitución. / Hace hincapié en que se debe superar el maniqueísmo, porque si se ve de dónde vienen las cosas, por qué esta persona es mala, por qué esta persona quedó por fuera de mi código ético o por qué esta persona se ha deshumanizado, necesariamente llegamos a algo mucho más complejo, y en 
una alianza, a un aniversario, a un retorno del año, a una fecha. Mas no a cualquiera, sino una de esas "fechas invisibles, ilegibles quizá: aniversarios, anillos, constelaciones y repeticiones singulares, únicos e irrepetibles: «unwiederholbar»" (Derrida, 2002, p. 13).

Ahora bien, ¿qué es lo irrepetible? A lo mejor ¿"algo de nuestro propio pasado que vuelve a la memoria"? (Derrida, 2002, p. 13). Cualquiera sea la respuesta, resulta incuestionable que lo irrepetible es lo único que se guarda en la memoria y que en algunas ocasiones se revela de manera contundente como en Shibboleth. Empero, ¿qué es lo que se revela en Shibboleth? ¿Qué "habla” allí? Para Derrida es claro: una fecha, la cual se hace patente en el poema; para nosotros, una grieta, como la de la escultura de Doris Salcedo. Dicho de modo taxativo, Shibboleth es resistirse a que un evento significativo e irrepetible se diluya sin más en el tiempo. De este modo, lo que busca Shibboleth, tanto el poema como la escultura, es que lo rememorado vuelva a tener sentido, "hoy, ahora para nosotros" (Derrida, 2002, p. 18). En sucintas palabras, en Shibboleth "habla" lo más arraigado en lo profundo de nosotros mismos. Aquello de lo que no es permitido guardar silencio: la herida.

De ahí por qué considera Jacques Derrida que Shibboleth "no [solo] es [el] absoluto de eso mismo que no puede retornar: un nacimiento o una circuncisión [por ejemplo, que] solo tiene lugar una vez, está más claro que el agua. [Sino] la retornancia (revenance) espectral de eso que, habiendo venido al mundo una sola vez, no volverá jamás” (Derrida, 2002, p. 36). Expresado de otra manera, Shibbo-

ese proceso nos vamos a ver involucrados siempre, mientras que, por el contrario, la gente prefiere no involucrarse, no asumir ningún tipo de responsabilidad. El mundo está vuelto nada. ¿Yo tengo la culpa? Sí, sí, sí la tenemos, claro que sí la tenemos. Recuerda entonces a Emmanuel Lévinas: Sí tengo la culpa porque llegué tarde, siempre llego tarde a mi responsabilidad; tengo una responsabilidad y llegué tarde, y se refiere a un personaje de Los hermanos Karamazov, que dice precisamente que es responsable de todo, de todo y por todo. / Entonces las preguntas son ¿Qué puedo hacer yo? ¿Qué debo, qué tengo que estar haciendo? ¿Por qué llegué tarde? Porque evidentemente el mundo se está cayendo a pedazos, y la que nos permite llegar hasta allí es la memoria histórica. Se trata de comprender de dónde venimos, de dónde vienen las cosas; cuando entendemos vemos que de pronto el otro no es tan malo y nosotros no somos tan buenos. La memoria inmediata, la memoria reciente, por el contrario, borra las demás. Entonces, ahí entra la función del arte y por eso el artista ha de ser una persona con una cierta estructura, y cada obra debe tener un grado de investigación alto, para poder llegar a contar una historia más compleja, no tan simplona, no tan elemental. Entender la complejidad, que hay muchas capas. Pero la vida se simplifica y esa simplificación polariza" (González, 2010). 
leth es el lugar donde se hace manifiesta la herida de una comunidad de "duelos no elaborados", la fractura que se hace patente en cada uno de esos crueles episodios que han terminado desgarrando a toda una colectividad, la fisura existente entre los seres humanos a causa, en muchos casos, de matices casi imperceptibles. Esto lo saben bien Celan y Salcedo. Nada insólito, si se tiene en cuenta que este vocablo se refiere a un hecho de la historia del pueblo judío en el que Jefté utilizó esta voz como santo y seña para derrotar a los efraimitas. Jacques Derrida resume esta infame historia en los siguientes términos:

Para impedir que los soldados [de Efraín] se escapasen pasando el río (Shibboleth significa también río, desde luego, pero no radica ahí la razón de esta elección), se le pedía a cada uno que dijese schibboleth. Ahora bien, los efraimitas eran conocidos por su incapacidad para pronunciar correctamente la Shi de schibboleth, que para ellos se convertía por tanto en una palabra impronunciable. Decían sibboleth y, en esta frontera invisible entre schi y si, se delataban al centinela con riesgo de su vida ["en aquella ocasión, murieron cuarenta y dos mil hombres de Efraím” anota Jue. 12: 6]. Delataban su diferencia haciéndose indiferentes a la diferencia diacrítica entre $s c h i$ y $s i$; se marcaban por no poder re-marcar una marca codificada de esta forma. (Derrida, 2002, p. 44)

De este modo, Shibboleth no hace más que mostrar la fractura propia de una época, de un pueblo, en la (el) que parece intensificarse cada vez más "la fragilidad de la vida, del ser humano y el hecho de que somos finitos" (Cubera, s.f.). Señalar aquello digno de permanecer en la memoria de una comunidad, de ser recordado, aunque produzca vergüenza. No está demás anotar que la obra artística de Salcedo está inspirada, en gran medida, en acontecimientos disruptivos "dignos" de ser evocados. Valga recordar, en este momento, su instalación Palacio de Justicia (6 y 7 de noviembre de 2002), cuyo tema principal fue la sangrienta toma del Palacio de Justicia en la ciudad de Bogotá en noviembre de 1985. Igualmente, la instalación Acción de duelo llevada a cabo el 3 de julio de 2007, esta vez tomando como punto de partida el asesinato de los diputados del Valle del Cauca en circunstancias poco claras. Por otra parte, tampoco sobra tener presente los museos, esos lugares que se han convertido en verdaderas resistencias al olvido en diversos sitios del mundo, como lo son: Auschwitz-Birkenau, el Museo de la historia de los judíos polacos en Austria, El Museo del Holocausto en Viena, El 
Gulag Museum de Moscú, el Perm-36 en Churchino; en Argentina, el Museo de la Memoria de Rosario, el Museo de Arte y Memoria y el Museo de la Memoria en Buenos Aires, sus equivalente en Chile y Perú o el famoso Monumento en la ciudad de Berlín a los judíos asesinados bajo el régimen nacionalsocialista.

Así, se puede decir que en Shibboleth "habla" una voz en la que confluyen todas las voces: las nuestras, y una herida en la que se hacen manifiestas todas las heridas. La grieta generada por todos aquellos que consideran, $v . g r$., que el uso "inadecuado" de su lengua implica una "seria" ruptura, es decir, esa fisura que en Europa no cesa de crecer: la xenofobia. Tal es la razón de por qué en Shibboleth convergen las voces de todos los que han sido excluidos. De ahí que Shibboleth se sitúe en la esfera misma de la desgarradura, del umbral, de la frontera, del límite. De manera más contundente, Shibboleth es "la memoria de olvido mismo, la verdad del olvido. (...) El Meridiano [donde todo] vuelve a la memoria" (Derrida, 2002, p. 62). Más claramente, Shibboleth es memoria, el lugar de la resistencia. Es una Acción de duelo en la que "todos los seres que lloramos en ese duelo, todos los dolores que se recogen [en] el poema [de Celan, en una escultura como la de la Salcedo, se resisten], a la borradura" (Derrida, 2002, p. 64). Pero si Shibboleth es resistencia al olvido, memoria ¿cómo debemos entender esta última? Para dar respuesta acudiremos a uno de los pensadores más controvertidos e influyentes del siglo XX: Martin Heidegger.

2. Memoria o el llamado de las aves migratorias

POR El momento no Ha Quedado otro camino que dejar "hablar" a Shibboleth, a la herida. En pocas palabras, a la resistencia al olvido, pues allí, se trae a la memoria eso que solo es posible una sola vez. Pero, ¿qué significa traer a la memoria? Quizá la respuesta la tenga, como se ha indicado, el autor de Ser y Tiempo, en tanto que él fue el encargado de dedicar, en el instante en el que el planeta entero estaba envuelto en llamas (1943), uno de sus ensayos más sugestivos al poema Memoria (Andenken) de Friedrich Hölderlin, del cual nos ocupamos brevemente ahora.

Como advierte Heidegger al inicio de su texto, el poema Memoria de Friedrich Hölderlin fue publicado en 1808, aunque su escritura data del año 1803 o 1804. Es decir, fue dado a conocer en una época en la que, gracias a las guerras 
napoleónicas, Alemania se hallaba en una aterradora encrucijada, resistir al ejército invasor en nombre de la libertad o someterse a los franceses de la manera más ignominiosa. Por otra parte, señala Heidegger, esta elegía hace parte de una serie de poemas con tema fluvial debidos a la pluma del insigne poeta suabo, de la que hace parte, también, el esbozo de poema que von Hellingran denominó «Ister $»^{6}$. En otras palabras, el poema Memoria integra esa serie de poemas con la cual Hölderlin "canta la esencia fluvial de ese río que en su curso superior fertiliza el lugar donde el poeta es originario" (Heidegger, 2005, p. 88). Pero veamos, a partir de un fragmento, que dice el poema:

\section{Memoria}

Sopla el Noreste,

para mí el más amado de los vientos,

pues promete espíritu y fuego

y viaje propicio a los navegantes.

Ve pues ahora y saluda

al hermoso Garona

y a los jardines de Burdeos.

[...]

Los días de fiesta allá mismo

se encaminan las morenas mujeres

sobre suelo de seda

en el tiempo de marzo

cuando son iguales la noche y el día

y sobre lentos senderos,

preñados de sueños dorados,

pasan aires arrulladores.

$[\ldots]$

6 Es pertinente tener en cuenta, como lo hace Martin Heidegger en su texto Memoria, el cual hace parte del libro Aclaraciones a la poesía de Hölderlin, que este término tiene su origen en el vocablo griego Istroz y hace referencia "al curso inferior del río al que los romanos también siguieron llamando «Ister» en su parte inferior, pero que llamarón «Danubio» en su curso superior" (Heidegger, 2005, p. 88). 
No es bueno

estar sin alma,

privado de pensamientos mortales. En cambio, bueno es

el diálogo y decir

lo que opina el corazón y oír contar muchas cosas

de los días del amor

y las hazañas ya acontecidas.

Pero ¿dónde están los amigos? ¿Dónde Belarmino

y el compañero? Algunos

sienten temor de ir a la fuente;

pues después de todo la riqueza comienza

en el mar.

[...]

Mas, ahora, a las indias

han partido los hombres,

desde allá, desde la cumbre batida de aire

en las colinas de viñas, desde donde

baja el Dordoña y al juntarse

con el magnífico Garona con anchura de mar

desemboca la corriente. En verdad, el mar

quita y da memoria,

y el amor también fija los aplicados ojos.

Pero lo que permanece lo fundan los poetas. (Hölderlin citado en Heidegger, 2005, pp. 89-90)

¿Qué quieren decir estas misteriosas palabras del poeta? Todo pareciera indicar, subraya Heidegger, que el poema hace referencia a un simple recuerdo de la estancia de Hölderlin en la ciudad francesa de Burdeos. Es más, no faltan, dentro de las cartas del poeta, alusiones que pueden llevarnos en esta dirección. Así que "de acuerdo con esta opinión, que parece la más obvia, el poema llevaría con evidente y pleno derecho su título": Recuerdo (Andenken) (Heidegger, 2005, p. 91). Pese a esto, declara el autor de Ser y Tiempo, cuando se hace un análisis más minucioso del poema, resulta evidente que en este se alude a algo mucho más fundamental. En este orden de ideas, subraya Heidegger (2005): 
[Al poeta se] le ha hecho conocer mejor [en este poema] el auténtico ser de los griegos. [En otras palabras] la estancia en lo extraño del cielo meridional esconde en sí para el poeta, de antemano y siempre, una verdad más alta: el «pensar» de este poeta «en» la tierra de los griegos ${ }^{7}$. Esta «Memoria» no tiene su origen esencial en la relatada estancia en Francia; en efecto, se trata de un rasgo fundamental del poetizar de este poeta, ya que para él la peregrinación a lo extraño es esencial para el retorno a la tierra natal, esto es, a la ley propia de su canto poético. [Por otra parte, manifiesta Heidegger,] la peregrinación poética a lo extraño tampoco termina con la partida a las tierras meridionales. El inicio de la estrofa final de «Memoria» señala, más allá de Grecia, hacia un Oriente más lejano, las Indias. El canto de este poema piensa por anticipado en ese lejano lugar extraño. (pp. 91-92)

No resulta fácil comprender estas palabras escritas por Heidegger. Y, sin embargo, de ellas es claro que cuando Hölderlin se vale de la palabra Memoria para nombrar su poema no se refiere a un simple recuerdo de algo pasado. Si así fuera, ¿por qué en un momento del poema se pregunta "pero ¿dónde están los amigos?"? Mal se haría en imaginar que con esta pregunta el poeta, simplemente, quiere informar acerca de un pasado del que participarían algunos amigos suyos. ¿No piensa más bien el poeta, manifiesta Martin Heidegger, en la marcha de estos "hacia la fuente y cómo lo ha sido"? Tal parece que, no obstante, esto entra en contradicción con el final del poema, a saber, con la hermosa afirmación: "lo que permanece lo fundan los poetas"; y es que no puede ser de otra manera. Cuando se reflexiona acerca del fundar, se piensa (denken), necesariamente, en (an) lopor venir. De este modo, habría que decir que, “«Pensar en $»$ An denken] lo que va a venir solo puede ser un «pensar en» lo ya sido, siempre que entendamos este término, y a diferencia de lo que sólo es pasado, aquello que desde entonces sigue siendo" (Heidegger, 2005, p. 93).

Para Heidegger es claro que Friedrich Hölderlin, en su poema Memoria (Andenken), no ha hecho otra cosa más que poetizar la esencia de la «Memoria». Mejor aún, "ha poetizado la esencia del pensar poetizador de los poetas venideros" (Heidegger, 2005, p. 93) y no un elemental recuerdo de viaje. Ahora bien, si

7 Como indican Helena Cortés y Arturo Leyte en una nota al pie de página al texto que venimos comentando, con la última formulación se arriba "a la interpretación del título «Andenken» ( «de entrada», «recuerdo») como «denken» «an», esto es, «pensar en»” (Heidegger, 2005, p. 91). 
no es un recuerdo de viaje, ¿de qué trata entonces el poema? Oigamos nuevamente su inicio:

Sopla el Noreste,

para mí el más amado de los vientos

pues promete espíritu de fuego

y viaje propicio a los navegantes.

Parece obvio, el poema habla del viento. Mas no de cualquier viento, sino de ese, reconoce Heidegger, que en dialecto suabo se denomina «el aire» (der Luft). Es decir, hace referencia a ese viento que "le presta una generosa estabilidad al clima y hace que madure el tiempo del ambiente despejado y sin nubes. [En condensadas palabras, a ese viento que], llama a los pájaros migratorios para que abandonen las tierras extrañas y regresen a la tierra natal a fin de que allí, puedan posar su mirada sobre lo suyo propio y cuidarlo" (Heidegger, 2005, p. 94). Formulado de otro modo, habla a propósito de aquellos más amados que "promete[n] espíritu de fuego y viaje propicio a los navegantes": los poetas ${ }^{8}$.

Sublimes palabras, sin lugar a dudas, pese a ello, aclara el filósofo de Messkich, estas no se reducen a una simple acotación poética. En ellas se “«llama» a los poetas a encontrarse en el destino de su esencia histórica. [Mejor aún, en estas] la Memoria es un pensar hacia adelante, hacia el destino esencial [del] poeta. [Es decir] la apertura del espacio de tiempo en el que la voluntad esencial es voluntad «de» lo venidero" (Heidegger, 2005, p. 96). Entendida esta última, no como una voluntad egoísta o voluntad de poder, sino como la determinación de hacer parte del destino de lo que resulta más entrañable y, que solo se puede reconocer completamente, habiendo sido un enajenado, un extranjero. En resumidas palabras, aquello cuya fundación histórica ha sido dada al poeta: la tierra natal (Heimat) 9 .

8 Esta palabra, desde luego, debe ser entendida, de aquí en adelante, en un sentido amplio, como aquellos que permiten traer a la presencia el ser de lo ente y la poesía como el lenguaje originario, "el acontecimiento de este decir en el que a un pueblo se la abre históricamente su mundo" (Heidegger, 1996, p. 63-64).

9 Nótese que aquí se ha utilizado la palabra Heimat (tierra natal) de la cual se vale Heidegger, a saber, de un vocablo en cuya raíz está en el término alemán Heim (hogareño) y no Vaterland (patria) y, mucho menos, se ha utilizado la voz Vaterländerei (patriotería) en el sentido utilizado por Nietzsche en Mas allá del bien y del mal (v. gr. aforismo 245). 
Por esta razón, para los mortales, si quieren apostar por la apertura del espacio de tiempo en el que la voluntad esencial es la voluntad «de» lo venidero, no resulta extraño obedecer el principio: "lo propio debe aprenderse tan a fondo como lo ajeno” (Heidegger, 2005, p. 97). Pues, solo así, reclama Heidegger, les será permitido a todos los hijos de la tierra "estar poéticamente en casa. (...) fundar y construir la polis” (Heidegger, 2005, p. 97), precisar el ámbito de lo político. De este modo, se entiende que solo podemos concebirnos a nosotros mismos en un diálogo profundo con lo que nos resulta extraño. Por tanto, una palabra como Shibboleth no solo sería una voz que separa la herida abierta sino, al mismo tiempo, eso que nos hace comprender nuestro ser más propio. Así, solo quien ha sido un extraño le será dado retornar a casa.

¿Cómo "dialogar", entonces, con quien nos resulta radicalmente extraño? Es más, ¿ “dialogar” con quien, incluso, nos ha causado un dolor insoportable? ¿Con aquel que ha dejado una herida imborrable en lo más insondable de nuestro propio corazón? ¿Cómo establecer un canal de comunicación con aquel que ha dejado en nosotros algo imposible de racionalizar: el sufrimiento? De ahí que Juan Manuel Garrido, en su ensayo titulado "Una pizca de sentido. Acerca de Entre Celan y Heidegger de Pablo Oyarzún”, pueda decir:

[El dolor] no ha de poseer ninguna «significación», so pena de ser neutralizado y obliterado como dolor. [Y, no obstante, asevera este autor a reglón seguido] solo la absurda crudeza del dolor, a título de acontecimiento [Ereignis] traumático que retorna excediendo la identidad temporal de una conciencia colectiva - es la función de la «data» en la poesía de Celan-, puede dar origen a una memoria y una historia auténticas. (Garrido, 2008, p. 81)

Expresado de esta manera, podemos decir, entonces, que el dolor no es tan solo algo que le atañe a la existencia de un individuo, aunque se encarne en ella, sino que se instaura como un acontecimiento [Ereignis] traumático que se arraiga en la conciencia de una colectividad. De esta suerte, siguiendo a Garrido, habrá que sostener que solo el dolor da origen a la memoria y la historia auténticas de una determinada comunidad, puesto que este es capaz de "hablar" desde la herida, incluso en la brumosa distancia que otorga a los seres humanos el tiempo ${ }^{10}$.

10 Cabe esperar que lo expuesto en las líneas anteriores cree cierta incomodidad en aquellos que creen en la memoria desde una perspectiva más optimista, y están en su todo derecho; sin embargo, no 
Así, según la expresión de Heidegger a propósito de la poesía de Georg Trakl en De camino al habla, el dolor es lo que separa y reúne, lo vinculante y lo que desgarra al mismo tiempo, "«lo articulador en el desgarrar que separa-y-reúne»" (Garrido, 2008, p. 84) ${ }^{11}$. A pesar de ello, quiérase o no, el acontecimiento traumático para todo un pueblo solo es posible al ser vulnerado el cuerpo de los individuos que componen dicha comunidad. Por ello, no es fortuito que el poeta Paul Celan vea en el dolor, como lo evidencia Juan Manuel Garrido en su texto, aquello que siempre remite al desgarramiento. De este modo, el dolor no es tan solo lo que separa y reúne, sino la juntura que separa, puesto que siempre remite al lugar mismo de "la comparecencia del dolor" (Garrido, 2008, p. 85) y en el que se hace patente de forma decisiva la propia mortalidad del ser humano: su cuerpo. De ahí la razón por la que el dolor, la herida, dé origen a "la memoria e historia auténticas" de una comunidad o, lo que es exactamente lo mismo, reúna a partir de la juntura que separa, pues el dolor debe remitir, inevitablemente, a lo que Garrido llama cuerpo herido; en palabras del autor:

Cuerpo herido, y herido a muerte, cuerpo muerto, cuerpo que pierde sangre, es decir, -porque está muerto- no pierde nada ya. (...) [Manifestado de forma más contundente, debe hacer referencia a] lo muerto en su estado de cruento, (...) [a la] «llaga misma», en sí misma. «Lo crudo; la carne viva, sangrante, que sigue testimoniando vida aún en la muerte, porque sangra»; lo crudo: la llaga misma. (...) [Acerca de] la herida que no cierra, para la herida que ni siquiera tiene el sentido («articulador en el desgarrar que separa-yreúne») de una herida. [En suma, acerca de esa herida sobre la que nada se funda] pues para fundar, para instituir, para crear -la historia, la comunidad-, la herida debe dejar de ser mera herida y debe poder incorporarse al

se puede negar la importancia de las experiencias traumáticas para la historia y la memoria de las comunidades humanas. Quien desee complementar su investigación a este respecto podrá dirigirse a los trabajos de Maurice Halbwachs, en particular, su libro titulado La mémoire colective.

11 Vale la pena transcribir aquí las palabras de Heidegger en el texto referido: "Mas ¿qué es el dolor? El dolor desgarra es el desgarro. Con todo, no desgarra en astillas que se desparraman. Ciertamente el dolor desgarra des-juntando; separa, pero de modo que, al mismo tiempo, reúne todo en sí. En tanto que separación, su desgarro es, a la vez, el tirar que, con trazo primero abriendo de pronto el espacio, dibuja y junta lo que se mantiene separado en la dis-junción. El dolor es el desgarro es lo unitivo que reúne y separa. El dolor es la juntura del desgarro. Ella es el umbral. Ella lleva a término el Entre, el Medio de los dos que están separados en él. El dolor junta el desgarro de la diferencia. El dolor es la Diferencia misma” (Heidegger, 1990, p. 25). 
sentido. Cruda la herida se Ex-cribe ${ }^{12}$ de la historia y de la comunidad, se excribe incluso de su nombre «herida $»$, y de todos los nombres que la nombran, para dejarla abierta, para endeudarnos o para cicatrizarnos: «Shoah», «holocausto», «exterminio», «mal», etc. Cruda, la herida se ex-cribe de todos los nombres del hombre para la insensatez de la historia. [Esto es, acerca de aquello que] se incrusta en la memoria y obliga a pensar. (Garrido 2008, pp. 85-86)

Pero, ¿qué sentido se le pueden dar a estas certeras palabras? A partir de lo dicho por Juan Manuel Garrido, que ha tomado como punto de partida lo planteado por Pablo Oyarzún a propósito de Martin Heidegger y Paul Celan, la respuesta a esta pregunta es clara: "para instituir, para crear -la historia, la comunidad-, [el dolor], la herida, [«la llaga misma»] debe dejar de ser mera herida y debe poder incorporarse al sentido [mismo] de la historia y de la comunidad". En sucintas palabras, si una colectividad quiere realmente fundar una historia y una memoria genuinas, si quiere realmente sanar, lo irrepetible, lo acontecido una sola vez, no debe dejar de doler, pues "solo lo que no cesa de doler permanece en la memoria” (Nietzsche, 1992, p. 118).

Mas ¿qué es eso que no deja de doler y permanece en la memoria? La respuesta se muestra de forma contundente: lo muerto en su estado de cruento, lo crudo, la llaga misma, esto es, todos nuestros muertos. Los del presente y los del pasado, a los que recordamos con una tristeza tan profunda, solo comparable al paisaje que nos brinda una insondable herida como aquella representada por Doris Salcedo en su obra Shibboleth. Esos, cuyas muertes atroces, nos hacen sentir como extranjeros en nuestra propia tierra. Y, ¿ ¿cómo no iba a ser esto así, si a muchos de ellos les fue arrebatada la vida de la manera más ignominiosa? De ahí el porqué de nuestra resistencia al olvido, de nuestra lucha a que cada uno de nuestros muertos permanezca en la Memoria. Desde esta perspectiva, hay que decir, entonces, que Memoria (Andenken) no es otra cosa que pensar-en (Andenken) la herida misma, en el dolor por los ausentes, incluso en los días de fiesta.

12 Sobre este extraño giro Garrido (2008) anota lo siguiente: “«lo excrito» es el término de Jean-Luc Nancy que Oyarzún emplea varias veces para describir este «fuera del lenguaje» al que nos abre la singularidad radical y absurda del poema” (p. 83). 
Esto lo sabe bien el poeta Friedrich Hölderlin cuando canta en su poema Los titanes:

Sin embargo, otórgame en las horas de fiesta,

y para que pueda reposar, que yo piense

en los muertos. Muchos han muerto,

capitanes de tiempos antiguos

y bellas mujeres y poetas,

y en los nuevos

muchos hombres.

Pero yo estoy sólo. (Hölderlin citado en Heidegger, 2005, p. 141)

Enunciado de este modo, para fundar la historia auténtica de una comunidad es menester que se haga manifiesta la herida misma, que nuestros muertos no nos dejen de doler. Esto fue, justamente, lo que comprendió (aunque resulte paradójico nombrar al último de los humanistas al lado del más furibundo crítico del humanismo, Martin Heidegger) un hombre que siempre se consideró a sí mismo una herida abierta: el artista Joseph Beuys. Ese ser humano que, al mismo tiempo, juzgó "la herida y la curación como vías de conocimiento y liberación" (Martínez, 2010). Ese hombre que "recurre al tratamiento del cuerpo como [quien trata] una herida" (Piedrahita, 2008). Pero que, ante todo, estimó que el quehacer del artista, algo que comprende muy bien Doris Salcedo, consiste en mostrar las heridas. Este es, precisamente, el nombre que le dio Beuys a su instalación acerca de Auschwitz, con el firme propósito de ayudar a curar una sociedad gravemente enferma tras la devastadora guerra que asoló a Europa desde 1939 (tal vez sea esta, después de Auschwitz, la labor más urgente no solo del arte sino de la filosofía). En suma, para que una comunidad, si se quiere efectivamente curar, funde una historia y una memoria auténticas, es decir tenga voluntad de lo venidero, resulta indispensable entablar un diálogo permanente con cada uno de nuestros muertos, dejar que broten de lo más profundo de nuestras entrañas aquellas heridas que yacen en lo profundo de nuestro ser, y fijarlas para siempre en la memoria de la colectividad.

Parece que lo único que resta aquí, tras estas contundentes palabras, no sea más que poner un punto y aparte. Sin embargo, antes de esto, se torna necesario, primero, dar un paso adelante y esbozar algún posible tratamiento a nuestro ya largo padecimiento. Para ello, finalmente, en lo que sigue, aunque resulte un tanto 
paradójico como se ha insistido, se dejará oír la voz de Joseph Beuys al lado de la de Martin Heidegger. ¿Qué mejor elección que estos dos hombres que fueron capaces de escudriñar en lo más recóndito de una época aquejada por la más terrible de las enfermedades: el cansancio? Pese a esto, resulta claro que, tal como vio el primero de ellos, "las enfermedades son casi siempre crisis espirituales de la vida, en las que se expulsan viejas experiencias y viejos procesos, o se transforman, como en un crisol, de un modo totalmente positivo" (Stachelhaus, 1990, p. 61).

¿Quién más había podido expresarse de este modo sino Joseph Beuys, que soportó, hasta el fin de sus días la terrible carga de haber sido el tenebroso instrumento encargado, como combatiente en la Segunda Guerra Mundial, de llevar tanto sufrimiento a diversos pueblos? Beuys lo sabía cabalmente, pues él mismo fue curado de sus mortales heridas, de manos de quienes el régimen de su propio país consideraba sencillamente seres inferiores a los que se debía eliminar sin ningún reparo: la daga que hiere es la misma daga que cura. Con razón, Martin Heidegger amaba citar estas hermosas palabras del poeta Hölderlin: "pero donde hay peligro, crece también lo que salva". Sea este el momento de darle a cada uno de ellos la palabra, llevando grabada en el corazón esta formidable sentencia del poeta que supo custodiar durante años, pese a su locura, la famosa torre a orillas del Neckar.

3. En verdad el mar quita y da memoria Incluso en la herida continúa habiendo una fuerza curativa. F. Nietzsche

La obra De Joseph Beuys, no cabe la menor duda, es la síntesis de una era cincelada por el mismo espíritu que esculpió a Shibboleth, a saber, el alma de la herida abierta, el nihilismo. Su obra es el compendio mismo de una época que terminó por acentuar la fractura que ha caracterizado, hasta el día de hoy, la relación existente entre los seres humanos y de estos con la naturaleza. Y, no obstante, al mismo tiempo, se erige como la sinopsis de una época en la que, según la expresión de otro humanista convencido Fromm (2004): "el hombre [aunque todavía] debe vivirse a sí mismo extraño en el mundo, como ajeno a sí mismo y a la naturaleza, para poder volver a ser consigo mismo, con sus semejantes y con la 
naturaleza, debe tener conciencia de la escisión que hay entre él como sujeto y el mundo como objeto, como condición para vencer esta misma escisión” (pp. 113114). Algo del todo evidente, desde luego, también para nuestro propio país.

Pero, ¿̇cómo evidenciar la escisión? Al parecer no hay otra alternativa que aceptar que existe una abismal brecha económica entre los hombres, mostrar las heridas, tal como lo anuncia la obra de Joseph Beuys a la que se ha hecho alusión más arriba ${ }^{13}$. Dejar "hablar" la herida abierta por el nihilismo, dejar "hablar" a Shibboleth, puesto que solo de esta manera será posible hacer brotar la vida de las cenizas del gran cansancio ${ }^{14}$; aliviar, de cierta forma, las heridas y, así, llamar a encontrarse con "el destino de [nuestra] esencia histórica". Un buen ejemplo de ello, en el ámbito del arte, se puede encontrar en otra de las instalaciones llevadas a cabo por Joseph Beuys tras la guerra. Nos referimos, desde luego, a su conocida Auschwitz demonstration. En lo que concierne a nuestro país, vale destacar, en

13 Sobra decir, como se indicó al inicio de este texto, que esta labor no fue exclusividad de un artista como Joseph Beuys, además de él, valga recordar de nuevo los ya mencionados Otto Dix, Max Beckman y Pablo Picasso, artistas que su momento fueron capaces de mostrar las heridas de forma contundente, al punto que sus obras se convirtieron en verdaderos íconos del sufrimiento humano; piénsese, por ejemplo, en lo que representa Guernica para la historia del arte en el siglo XX.

14 Estas conmovedoras palabras se deben a la pluma de Edmund Husserl las cuales se encuentran al final de su memorable conferencia La crisis de la humanidad europea y la filosofia, impartida en el círculo cultural de Viena los días 7 y 10 de mayo de 1935 y en las que se puede leer: "Aunemos considerablemente las ideas de nuestros desarrollos: la «crisis de la existencia europea», de la que hoy tanto se habla y de la que dan testimonio tantos síntomas de descomposición de la vida, no es un oscuro destino, no es una fatalidad impenetrable, sino que resulta inteligible y aprehensible desde el trasfondo de la teleología de la historia europea que la filosofía está llamada a descubrir. Supuesto previo de la comprensión es, sin embargo, que el fenómeno «Europa» sea comprendido antes en su núcleo esencial central. Para poder comprender la confusión de la «crisis» actual, tendría que ser reelaborado el concepto de Europa en tanto que teleología histórica de fines infinitos, tendría que mostrarse como el «mundo» europeo fue alumbrado a partir de ideas racionales, esto es, desde el espíritu de la filosofía. Pero la raíz del fracaso de una cultura no radica -como ya quedó dicho-en la esencia del racionalismo como tal, sino sólo en su cosificación alienada, en su degradante revestimiento con los ropajes del «naturalismo» y del «objetivismo». / La crisis de la existencia europea tiene dos salidas: la decadencia de Europa en la alienación respecto de su propio sentido racional de la vida, la caída en el odio espiritual y en la barbarie, o el renacimiento de Europa desde el espíritu de la filosofía mediante un heroísmo de la razón que supere definitivamente el naturalismo. El mayor peligro de Europa es el cansancio. Luchemos contra este peligro de los peligros como «buenos europeos» con la valentía que ni siquiera se arredra ante una lucha infinita; resurgirá entonces de la brasa destructora de la incredulidad, del fuego lento de la desesperación sobre la misión de Occidente respecto de la humanidad, de las cenizas del gran cansancio, el Fénix de la nueva vida interior y de una espiritualidad nueva, garantía primera de un futuro grande y remoto para la humanidad: porque solo el espíritu es inmortal" (Husserl, 1991, pp. 357-358). 
esta misma dirección, la formidable pintura Violencia de Alejandro Obregón (1962) y, de manera más reciente, la obra Atrabiliarios (1993), y las ya mencionadas Palacio de Justicia (2002) y Acción de Duelo (2007) de Doris Salcedo.

Cabe subrayar que esta forma de hacer arte no solo genera un cambio radical en el modo de verlo y en el papel del artista dentro de la sociedad sino, y esto es lo que resulta más importante, se abre así el lugar por excelencia de la resistencia al olvido: la memoria, la cual se constituye en el primer paso en el camino hacia la cura. En otras palabras, el artista "se encuentra con el destino de su esencia histórica". En últimas, como pensaba Hölderlin, le es dado fundar lo que permanece. Pero, ¿cómo encontrar la cura en una sociedad gravemente enferma? Para Joseph Beuys la respuesta resulta clara, cuando apuesta por lo que él llama plástica social o, si se prefiere, cuando se hace de la misma sociedad una obra de arte. De ahí la importancia que le da el artista alemán a la educación. Sin embargo, ¿esto no resulta ser solo una simple quimera?

Tal parece que para Beuys, en palabras de Heidegger, si los seres humanos aspiramos a una nueva forma de relacionarnos entre nosotros y con la naturaleza, se hace ineludible no solo una nueva manera de interpretar el ser de lo ente, sino una nueva forma de ser en el ser, que nos lleve de la enajenación al concepto ampliado de arte. Es decir, de una relación de sufrimiento con lo que existe, a una relación en la que, incluso el trabajo, esté mediado por un principio de creatividad. En otros términos, una nueva forma de ser en el ser que lleve de una interpretación de lo ente, básicamente negativa, a una donde se "fomente vida, alma y espíritu" (Stachelhaus, 1990, p. 74) y, en la que el arte, entendido en un sentido amplio, se erija en una "terapia prometedora de éxito para curar a la larga las heridas individuales y sociales" (Stachelhaus, 1990, p. 176). Con razón escribió Friedrich Nietzsche en uno de sus Escritos Póstumos: “El arte y nada como el arte! Es el gran posibilitador de la vida, el gran estimulante de la vida, como lo anticristiano, antibudista, antinihilista, por excelencia” (Nietzsche, 1998, p. 168).

Esto significa una nueva manera de existir en la que se asuma, al modo que lo hizo Beuys que, "sin dolor no hay conciencia" (Stachelhaus, 1990, p. 181). Y, manifestado de una manera más significativa para nuestro propio contexto, un nuevo modo de ser en esta tierra en el que por fin se haga el duelo en una patria 
de "duelos no elaborados" (González, 2010)15. Una nueva manera de ser en la que se traiga de nuevo "al campo de lo humano la vida que ha sido desacralizada" (Toledo, 2007). En último término, un nuevo modo de ser en esta tierra en la que, invariablemente, "algo [esencial] de nuestro pasado [retorne] a la memoria" (Derrida, 2002, p. 13) para que esta vuelva a tener sentido, aquí y ahora, para nosotros. De modo más preciso, para que en este momento de la historia seamos capaces de construir "la memoria del olvido mismo, la verdad del olvido" (Derrida, 2002, p. 62), puesto que, solo allí, se darán cita lo extraño y lo propio, lo ausente y lo presente, la vida y la muerte. ¿ No era esto, precisamente, a lo que se refería Friedrich Hölderlin cuando escribió: "no es bueno estar sin alma, privado de pensamientos mortales"?

En este sentido, habrá que decir que esta nueva manera de ser-en-esta-tierra implica, necesariamente, el reconocimiento de nuestra propia levedad. En última instancia, que lo más vinculante, lo que nos hace ser parte de una comunidad de seres humanos es, además de nuestros lazos más íntimos, el sufrimiento. Con razón anotó Beuys: tenemos conciencia del dolor porque amamos la vida. Así las cosas, en una tierra signada por el dolor -y esto también lo sabía Joseph Beuys-, solo la conciencia de la muerte nos mantiene despiertos. Cuando seamos capaces de comprender esto nos será dado abrir el camino que nos permita suturar las heridas, sortear la fractura, conjurar el nihilismo; nos será permitida, al modo de Heidegger, "una nueva donación del Ser" (Heidegger, 1994, p. 53).

Con todo, como se puede ver, esto no es más que una utopía; y, una utopía de seres humanos de carne y hueso, a los que les ha sido negado suplir sus necesidades más básicas. Una utopía en la que no se sacrifique a ningún hombre en nombre del desarrollo, del capital, de la moralina o de una ideología. En síntesis, una utopía en la que se reivindica, del mismo modo que lo hizo Joseph Beuys hasta el día de su muerte, la "tolerancia activa”, el "trabajo para todos", la remuneración para el ama de casa. En último término, una utopía en la que todo ser humano es soberano, puesto que la revolución somos nosotros [rivoluzione siamo Noi].

15 No está de más recordar que ya se han hecho intentos en este sentido en nuestro país. Prueba de ello lo constituye la creación del Centro Nacional de Memoria Histórica y la participación de las víctimas del conflicto interno en los diálogos entre el Estado colombiano y las Farc en La Habana, Cuba. 
En otras palabras, la utopía de las causas a favor del medio ambiente, del triunfo de eros y del arte, en la que se pone decididamente la cara al sufrimiento, al miedo, a la nada. Una utopía en la que se está abierto al pensar que rememora (Andenken), a la resistencia al olvido, en la era, según la expresión de Heidegger, del dominio planetario y la lucha por la "disputa del ser"(Heidegger, 2000, p. 343). El dorado sueño de ese que habiendo sido largo tiempo extranjero en tierras extrañas, ha estado enajenado, vuelve a la tierra natal, mas no como lo hace un enfermo de patriotismo, sino para cuidarla en común y, a partir de allí, abrir el mundo al porvenir. En tales condiciones, "el ser humano no es ya un artista, se ha convertido en una obra de arte" (Nietzsche, 1984, p. 44-45). Como es de suponer, en un mundo constituido de este modo se ha liberado a todos los combatientes y se les ha otorgado "un mismo derecho, es decir, el propio de cada uno: el tener su propio ser” (Heidegger, 2005, p. 121).

Se está ante la utopía de quien ha permanecido enajenado y vuelve de tierras extranjeras con el firme propósito de instaurar un auténtico morar sobre la tierra en [un] diálogo originario con lo extraño, pues solo así le será posible encontrar su ser más propio, dialogar con todos los ausentes antiguos y modernos y rendirles homenaje. Esto es, honrar la memoria de cada uno de sus muertos, para construir así una tierra en la que se ponga "fin a esa lucha entre Yo y el mundo, restaurar la paz de toda paz, que es más alta que toda razón, reconciliarnos con la naturaleza y unirnos a ella en un único Todo infinito. [Dicho de otro modo, construir una tierra] en el que la belleza reine" (Heidegger, 2005, pp. 148-149).

Con esta dorada utopía soñó un día el autor del Primer programa del idealismo alemán, cuando pedía “iir más allá del Estado! [Para de esta forma instaurar una tierra en la que reine por fin la] libertad y la igualdad de todos los espíritus" (Hegel, 1978, pp. 219-220), pues allí, nos será dado por fin curar las heridas, la llaga misma, ya que estas se habrán incorporado finalmente al sentido mismo de la historia de nuestra comunidad. En definitiva, esta es la utopía de la reconciliación de Apolo y Dionisos en la que no se desprecia la vida, la naturaleza, el cuerpo, el aquí y el ahora. La utopía del heroísmo trágico, con la cual se ha sabido marchar "hacia la fuente [con el fin de comprender] como ha sido" para lanzarse valientemente al porvenir.

¿No son todas estas palabras, nada más que vanas ilusiones? Quizá. Con todo, esta no es la pregunta sustancial. Hoy resulta más urgente responder a pre- 
guntas como: ¿Dónde están los amigos ausentes? ¿Cómo superar la brecha entre los hombres? Y, sobre todo, a un cuestionamiento mucho más fundamental: “Por qué la nada y no más bien el ser?” (Ávila, 2005, p. 27). De la respuesta que se dé a estas preguntas dependerá si será posible para nosotros, en este preciso lugar y momento de la historia, desligarnos o no de un proyecto con el cual nos hemos empecinado en sumergir en un mar de sangre nuestro trágico destino. ¡Cuánta razón tenía el enajenado Hölderlin cuando dijo en uno de sus poemas de locura!:

"[L]a vida es la tarea del hombre en este mundo"

\section{Referencias}

Ávila, R. (2005). El desafio del nibilismo. La reflexión metafísica como piedad del pensar. Madrid: Trotta.

Celan, P. (1999). Obras completas. (Trad. J.L. Reina Palazón). Madrid: Trotta.

Celan, P. (1997). De umbral en Umbral. (Trad. J. Munárriz). Madrid: Hiperión.

Derrida, J. (2002). Schibboleth. Para Paul Celan. (Trad. J. Pérez de Tudela). Madrid: Arena Libros.

Garrido, J.M. (2008). Una pizca de sentido. Acerca de Entre Celan y Heidegger de Pablo Oyarzún. Revista de Filosofía, 64, pp. 79-88. Versión Online: http://www.scielo.cl/scielo.php?pid=S0718-43602008000100006\&script=sci_ arttext Recuperado: 02.04 .12

Goethe, J.W. (1968). Fausto. (Trad. J. Roviralta Borrell). Madrid: Universidad de Puerto Rico/Revista de Occidente.

González, G. (2010). Una grieta en el corazón de Europa. Versión Online: https://elaladearriba.wordpress.com/guillermo-gonzalez-uribe/periodismo/cultural/doris-salcedo-y-shibboleht/ Recuperado: 07.08.11

Hegel, G.W.F. (1978). Escritos de juventud. (Trad. Z. Szankay \& J.M. Ripalda). México D. F.

Heidegger, M. (2005). Aclaraciones a la poesía de Hölderlin. (Trad. H. Cortés \& A. Leyte). Madrid: Alianza Editorial.

Heidegger, M. (2000). En torno a la cuestión del ser. Hitos. (Trad. H. Cortés \& A. Leyte). Madrid: Alianza Editorial. 
Heidegger, M. (1996). El origen de la obra de arte. (Trad. H. Cortés \& A. Leyte). Madrid: Alianza Editorial.

Heidegger, M. (1994). Hacia la pregunta del ser. Acerca del nibilismo. (Trad. J.L. Molinuevo). Barcelona: Paidós.

Hölderlin, F. (2005). Poemas de locura. Precedida de algunos testimonios de sus contemporáneos sobre los "años oscuros" del poeta. (Trad. T. Santoro \& J.M. Álvarez). Madrid: Hiperión.

Husserl, E. (1991). La crisis de las ciencias europeas y la fenomenología trascendental. Barcelona: Crítica.

Fromm, E. (2004). El concepto profético de paz. La condición humana actual y otros temas de la vida contemporánea. (Trad. G. Steenks). Barcelona: Paidós Ibérica.

Martínez, N. (2010). Joseph Beuys. 25 años después y todavía. Versión Online: Arte-actual.blogspot.com/2010/10/Joseph-beuys-25-anos-despues-y-todavia.html Recuperado: 10.10.11.

Nietzsche, F. (1998). El nibilismo. Escritos póstumos. (Trad. G. Mayos). Barcelona: Península.

Nietzsche, F. (1992). La ciencia Jovial. "La Gaya Scienza". (Trad. J. Jara). Caracas: Monte Ávila Editores.

Nietzsche, F. (1984). El nacimiento de la tragedia. O Grecia y el pesimismo. (Trad. A. Sánchez Pascual). Madrid: Alianza Editorial.

Piedrahita, L. (2008). Joseph Beuys, el cuerpo como redención. Versión Online: www.ecbloguer.com/letrasanonimas/?p=533. Recuperado: 20.03 .12

Stachelhaus, H. (1990). Joseph Beuys. (Trad. J. Godo Costa). Barcelona: Parsifal ediciones.

Toledo, M. (2007). Doris Salcedo: canto al racismo. Versión Online: www. newsbbc.co.uk/hi/spanish/misc/newsid_7035000/7035694.stm. Recuperado: 29.06 .11 